\title{
Produção de prolina e suscetibilidade ao glufosinato de amônio em plantas transgênicas de citrumelo Swingle
}

\author{
Cristine Elizabeth Alvarenga Carneiro(1), Hugo Bruno Correa Molinari(2), Giselly Aparecida Andrade ${ }^{(1)}$, \\ Luiz Filipe Protasio Pereira ${ }^{(3)}$ e Luiz Gonzaga Esteves Vieira ${ }^{(1)}$
}

\begin{abstract}
(1)Instituto Agronômico do Paraná, Caixa Postal 481, CEP 86001-970 Londrina, PR. E-mail: Ivieira@iapar.br (2)Universidade Federal do Paraná, Dep. de Fitotecnia e Fitossanitarismo, CEP 81531-990 Curitiba, PR. E-mail: hb_molinari@yahoo.com.br (3)Embrapa Café, Pq EB, Av. W3 Norte, Ed. Sede, 3andar, CEP 70770-901 Brasília, DF. E-mail: Ipereira@iapar.br
\end{abstract}

Resumo - O objetivo deste trabalho foi avaliar a sensibilidade de plantas transgênicas de citrumelo Swingle com elevada produção de prolina, ao herbicida glufosinato de amônio. As plantas utilizadas apresentavam a inserção do gene mutante da enzima $\Delta^{1}$-pirrolina-5-carboxilato sintetase (P5CS), responsável pela biossíntese de prolina. A expressão do gene $p 5 c s$ em plantas transgênicas causou aumento nas quantidades de prolina em tecidos foliares, em até cinco vezes, quando comparadas às plantas-controle tratadas com $200 \mu \mathrm{M}$ de glufosinato de amônio. As plantas transgênicas acumularam maior quantidade de $\mathrm{NH}_{4}{ }^{+}$nas folhas, em relação às plantas nãotransgênicas. Os danos causados pelo herbicida foram avaliados in vitro, utilizando-se discos foliares cultivados em meio MS com diferentes concentrações de glufosinato de amônio. Observou-se maior clorose em discos foliares das plantas transgênicas, o que comprova a maior suscetibilidade de plantas de citrumelo Swingle com alta produção de prolina ao herbicida.

Termos para indexação: Citrus paradisi, Poncirus trifoliata, fosfinotricina, P5CS.

\section{Proline production by transgenic plants of Swingle citrumelo and susceptibility to glufosinate ammonium}

\begin{abstract}
The objective of this work was to evaluate the susceptibility to glufosinate ammonium of transgenic plants of Swingle citrumelo with high proline production. The mutant gene of the enzyme $\Delta^{1}$-pyrroline-5-carboxylate synthetase (P5CS), the rate-limiting enzyme in proline biosynthesis, was inserted into Swingle citrumelo plants. The expression of the gene $p 5 c s$ caused up to 5-fold increase on the proline content in leaf tissues of transgenic plants treated with $200 \mu \mathrm{M}$ glufosinate ammonium, when compared with control plants. Leaves of transgenic plants accumulated higher amounts of $\mathrm{NH}_{4}{ }^{+}$than the nontransgenic control. The herbicide toxicity was evaluated using leaf disks cultivated in MS medium, containing different concentrations of glufosinate ammonium. The severity of the chlorosis, observed in leaf disks of transgenic plants, confirmed the higher susceptibility of Swingle citrumelo plants, with high proline production, to this herbicide.
\end{abstract}

Index terms: Citrus paradisi, Poncirus trifoliata, phosphinothricin, P5CS.

\section{Introdução}

A engenharia genética de plantas, dirigida ao aumento de solutos compatíveis, como a prolina, é uma ferramenta promissora para aumentar a capacidade das plantas de tolerar o estresse hídrico. Plantas transgênicas de tabaco, que superexpressaram o gene $p 5 c s$, aumentaram a tolerância ao estresse hídrico e salino (Kishor et al., 1995). Plantas do porta-enxerto citrange Carrizo, transformadas com o gene mutante $p 5 c s$, acumularam altas concentrações de prolina nas folhas e, conseqüentemente, apresentaram maior tolerância ao estresse hídrico (Molinari, 2003).
Em plantas, o aminoácido L-prolina é sintetizado via glutamato e $\Delta^{1}$-pirrolina-5-carboxilato (P5C) por duas sucessivas reduções, as quais são catalisadas pelas enzimas P5C sintetase (P5CS) e P5C redutase (P5CR) (Hare et al., 1999) ou, alternativamente, a partir de ornitina, pela enzima ornitina $\delta$-aminotransferase -OAT (Lutts et al., 1999). O acúmulo de prolina também depende da sua via de catabolismo. A degradação de prolina em plantas é catalisada por duas enzimas. A prolina desidrogenase (ProDH) catalisa a conversão de prolina em $\Delta^{1}$-pirrolina-5-carboxilato (P5C) que é, então, oxidada a glutamato pela P5C desidrogenase (P5CDH) (Yoshiba et al., 1997). 
A via glutamato é predominante em plantas em condições de estresse osmótico e falta de nitrogênio (Delauney et al., 1993). Assim, a enzima P5CS é limitante para a biossíntese de prolina em plantas e é sensível à inibição por retroalimentação (Zhang et al., 1995). Tanto a enzima glutamina sintetase, como também a atividade $\gamma$-glutamil quinase, da enzima bifuncional P5CS, catalisam a fosforilação ATP-dependente de glutamato, para formar o intermediário glutamil fosfato (Hu et al., 1992).

O glufosinato de amônio, que tem como ingrediente ativo o L-isômero de fosfinotricina (L-PPT), é um herbicida de amplo espectro que inibe a enzima glutamina sintetase em cloroplastos, bloqueando a síntese de glutamina via glutamato e, portanto, a assimilação de $\mathrm{NH}_{4}{ }^{+}$(Manderscheid \& Wild, 1986). A inibição da glutamina sintetase resulta em acúmulo de $\mathrm{NH}_{4}{ }^{+}$e, conseqüentemente, na morte da planta. Fontes de $\mathrm{NH}_{4}{ }^{+}$nas células incluem a fotorrespiração, redução de nitrato e catabolismo de compostos nitrogenados (predominantemente aminoácidos), o que resulta no acúmulo de quantidades letais de $\mathrm{NH}_{4}{ }^{+}$(Joy, 1988). O glufosinato de amônio está registrado no Brasil e é utilizado para controle de ervas daninhas em diversas culturas, entre elas plantas cítricas.

Estudos recentes mostram que o acúmulo de $\mathrm{NH}_{4}{ }^{+}$ e prolina, em folhas de arroz, estão associados (Lin \& Kao, 2001). A aplicação de $\mathrm{NH}_{4} \mathrm{Cl}$, que causa acúmulo de $\mathrm{NH}_{4}{ }^{+}$em folhas destacadas de arroz, também aumenta a concentração de prolina nos tecidos foliares (Lin \& Kao, 2001). Como plantas transgênicas que superexpressam o gene $p 5 c s$ acumulam quantidades elevadas de prolina em condições normais, é possível inferir que tais plantas, quando submetidas à ação do herbicida glufosinato de amônio, também possam acumular maior quantidade de $\mathrm{NH}_{4}{ }^{+}$nas células, tornando-as mais suscetíveis à ação deste herbicida. Assim, plantas transgênicas, com alta produção de prolina, podem mostrar resposta diferencial à aplicação de herbicidas que atuam nos processos metabólicos envolvidos na utilização do nitrogênio.

O objetivo deste trabalho foi avaliar a sensibilidade de plantas transgênicas de citrumelo Swingle, com elevada produção de prolina, ao herbicida glufosinato de amônio.

\section{Material e Métodos}

Explantes originados de plântulas de citrumelo Swingle foram obtidos conforme descrito por Molinari et al. (2004a). A estirpe EHA105, de Agrobacterium tumefaciens (Hood et al., 1993), contendo o vetor binário pBI-P5CSF129A (Zhang et al., 1995), foi utilizada para transformação. Este vetor contém o gene indicador uidA, o gene mutante $p 5 c s$ de Vigna aconitifolia, ambos sob o controle do promotor constitutivo CaMV 35S, e o gene marcador de seleção nptII, sob o controle do promotor do gene da nopalina sintetase. O co-cultivo, seleção dos explantes transformados e micropropagação dos eventos de transformação foram realizados conforme Molinari et al. (2004a, 2004b). As plantas transgênicas e plantas-controle foram cultivadas em casa de vegetação.

A análise preliminar para verificar a inserção do transgene $p 5 c s$, em plantas de citrumelo Swingle, foi feita por meio de PCR, utilizando-se segmentos foliares dos brotos cultivados no meio seletivo. Para determinar o número de cópias do gene $p 5 c s$, nas plantas transformadas, foram feitos "Southern blots" de quatro eventos, segundo Sambrook et al. (1989). Como sonda para a hibridização, foi utilizado um fragmento de DNA de $1,6 \mathrm{~kb}$ do gene $p 5 c s$, obtido por meio da digestão do plasmídeo pBI-P5CSF129A com XbaI. A marcação da sonda foi feita, utilizando-se $\left[\alpha^{32} \mathrm{P}\right] \mathrm{d}-\mathrm{CTP}$, pela técnica de "random priming".

Discos foliares de $1 \mathrm{~cm}$ de diâmetro, cortados de folhas de mesma idade e tamanho, foram retirados de três clones do evento de transformação Ct-P5-20 e de três clones de plantas-controle e, em seguida, imersos em placas de Petri com: $20 \mathrm{~mL}$ de glufosinato de amônio $100 \mu \mathrm{M}$ ou $200 \mu \mathrm{M}$, e água destilada como controle. As placas de Petri, com dez discos foliares cada, foram mantidas por 8 horas em temperatura ambiente, sob luminosidade constante $\left(50 \mu \mathrm{mol} \mathrm{m}^{-2} \mathrm{~s}^{-1}\right)$. Após o período de incubação, os discos foram congelados em $\mathrm{N}_{2}$ líquido e armazenados a $-70^{\circ} \mathrm{C}$.

Foram realizadas as quantificações de prolina (Bates et al., 1973), de $\mathrm{NH}_{4}{ }^{+}$(D’Halluin et al., 1992), de proteína total (Bradford, 1976) e aminoácidos totais livres pelo ensaio da ninhidrina (Moore \& Stein, 1954), utilizandose dez discos foliares de $1 \mathrm{~cm}$ de diâmetro, incubados com água e glufosinato.

Folhas de plantas transgênicas, do evento Ct-P5-20, e de plantas-controle foram coletadas de plantas em casa 
de vegetação, desinfestadas com $\mathrm{NaClO} 1 \%$ e, posteriormente, lavadas com água deionizada. Seis discos foliares ( $1 \mathrm{~cm}$ de diâmetro) foram cortados e colocados em placas de Petri, em meio MS com 6-benzilaminopurina $(2,2 \mu \mathrm{M})$ e diferentes concentrações de glufosinato de amônio (100, 200, 400 e $800 \mu \mathrm{M})$. Após cinco dias, o efeito do glufosinato nas plantas foi avaliado, visualmente, nos discos foliares, quanto à escala de severidade dos danos. Este experimento foi repetido 3 vezes.

Para a análise dos teores de $\mathrm{NH}_{4}{ }^{+}$, aminoácidos e proteínas totais, o desenho experimental utilizado foi o inteiramente casualizado, num esquema fatorial $3 \times 2$, com seis repetições, representadas por uma placa de Petri, com dez discos foliares por tratamento (planta transgênica e não-transgênica tratadas com 0, 100 e $200 \mu \mathrm{M}$ de glufosinato de amônio).

No caso da quantificação de prolina, nove repetições foram utilizadas para cada tratamento. O experimento de avaliação da susceptibilidade a concentrações crescentes de glufosinato de amônio foi realizado usandose desenho experimental inteiramente casualizado num esquema fatorial $4 \times 2$, com seis repetições, representadas por uma placa de Petri com seis discos foliares para cada um dos oito tratamentos, quatro concentrações de glufosinato de amônio (100, 200, 400 e $800 \mu \mathrm{M})$ e dois tipos de plantas (transgênica e não-transgênica). Após a análise de variância, as médias foram comparadas pelo teste de Tukey a 5\% de probabilidade, utilizando-se o programa Genes (Cruz, 1997).

\section{Resultados e Discussão}

A variação no número de bandas detectadas e na posição de inserção do transgene no genoma das plantas, observada por "Southern blot", sugere que cada planta derivou de eventos de transformação independentes (Figura 1). Somente um evento (Ct-P5-20) apresentou uma única cópia do transgene. Nenhum sinal de hibridização foi detectado em plantas não-transgênicas.

$\mathrm{Na}$ análise de prolina em tecido foliar, enquanto as plantas-controle apresentaram concentrações que variaram de 12,28 a 17,71 $\mu \mathrm{M}$ de prolina por grama de massa fresca (MF), as plantas transgênicas de citrumelo Swingle apresentaram de 35,53 a 129,74 $\mu \mathrm{M}$ de prolina por grama de MF (Figura 2). O evento de transformação (Ct-P5-20) com uma única cópia do transgene, também apresentou as maiores concentrações de prolina, em relação às plantas- controle, e, por isso, foi escolhido para as análises subseqüentes (Figuras 1 e 2).

A quantidade de prolina acumulada em plantas transgênicas submetidas a $100 \mu \mathrm{M}$ de glufosinato não foi significativamente diferente da produzida pelas mesmas plantas tratadas somente com água (Figura 3 A). De modo semelhante, as plantas-controle incubadas com $100 \mu \mathrm{M}$ de glufosinato apresentaram concentrações similares de prolina nas folhas, em relação às tratadas somente com água (Figura $3 \mathrm{~A}$ ). A concentração de $100 \mu \mathrm{M}$ de glufosinato, portanto, não foi suficiente para causar um aumento do teor de prolina nas folhas, tanto nas plantas transgênicas quanto nas plantas nãotransgênicas.

No entanto, quando tratadas com $200 \mu \mathrm{M}$ de glufosinato, as plantas transgênicas apresentaram maior acúmulo de prolina (213,36 $\left.\mu \mathrm{M} \mathrm{g}^{-1} \mathrm{MF}\right)$, do que quando tratadas somente com água $\left(45,30 \mu \mathrm{M} \mathrm{g}^{-1} \mathrm{MF}\right)$ ou com $100 \mu \mathrm{M}$ de glufosinato $\left(47,69 \mu \mathrm{M} \mathrm{g}^{-1} \mathrm{MF}\right)$. Da mesma forma, este aumento proporcional de prolina foi observado em plantas-controle tratadas com $200 \mu \mathrm{M}$ de glufosinato (97,40 $\left.\mu \mathrm{M} \mathrm{g}^{-1} \mathrm{MF}\right)$, em relação às tratadas com água (13,56 $\left.\mu \mathrm{M} \mathrm{g}^{-1} \mathrm{MF}\right)$ ou com $100 \mu \mathrm{M}$ de

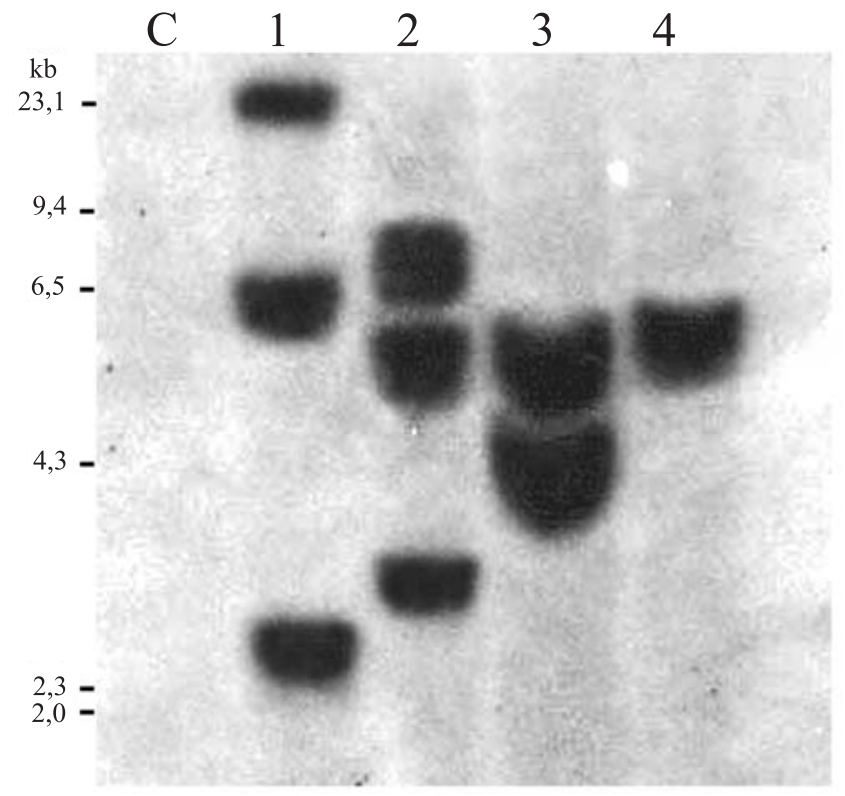

Figura 1. Análise de “Southern blot”, em porta-enxertos transgênicos. Canaleta C: controle negativo de citrumelo Swingle; canaletas 1 a 4: plantas transgênicas de citrumelo Swingle (1: evento Ct-P5-07; 2: evento Ct-P5-08; 3: evento Ct-P5-16; 4: evento Ct-P5-20). 
glufosinato (16,09 $\left.\mu \mathrm{M} \mathrm{g}^{-1} \mathrm{MF}\right)$. Estes dados estão de acordo com Tsai et al. (2003), que mostraram que segmentos de folhas de arroz incubados com glufosinato de amônio por períodos superiores a 8 horas induziram aumento significativo do acúmulo de prolina, em comparação com os segmentos tratados somente com água.

As concentrações de $\mathrm{NH}_{4}^{+}$, em folhas de plantas transgênicas e não-transgênicas tratadas com água, foram de 37,10 e 37,88 $\mu \mathrm{g} \mathrm{g}^{-1} \mathrm{MF}$, respectivamente, o que demonstra que sob condições normais a inserção do gene $p 5 c s$ não teve qualquer efeito no acúmulo de $\mathrm{NH}_{4}{ }^{+}$ (Figura $3 \mathrm{~B}$ ).

Foi observado um pequeno aumento na concentração de $\mathrm{NH}_{4}{ }^{+}$, em plantas transformadas e controle, quando tratadas com glufosinato na concentração $100 \mu \mathrm{M}$, não sendo esta diferença considerada estatisticamente significativa.

Com o aumento de glufosinato de amônio para $200 \mu \mathrm{M}$, a concentração de $\mathrm{NH}_{4}{ }^{+}$nas plantas transformadas foi de $50,69 \mu \mathrm{g} \mathrm{g}^{-1} \mathrm{MF}$, o que mostra uma diferença significativa das plantascontrole (44,9 $\mu \mathrm{g} \mathrm{g}^{-1} \mathrm{MF}$ ) (Figura $\left.3 \mathrm{~B}\right)$. Estas últimas, quando tratadas com glufosinato na concentração mais alta, não aumentaram significativamente o teor de $\mathrm{NH}_{4}^{+}$nas folhas, em relação às plantas tratadas com $100 \mu \mathrm{M}$; isto demonstra que o efeito do aumento da concentração de herbicida, no acúmulo de $\mathrm{NH}_{4}{ }^{+}$, foi mais evidente nas plantas transformadas. Estes

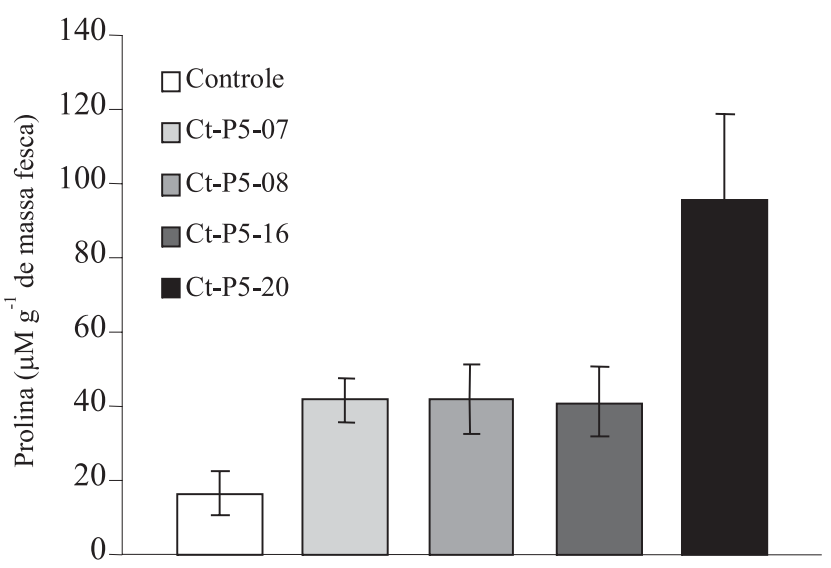

Figura 2. Concentração de prolina em folhas de planta controle (não-transformada) e em diferentes eventos de transformação. Os valores são apresentados como médiaさdesviopadrão $(n=4)$.
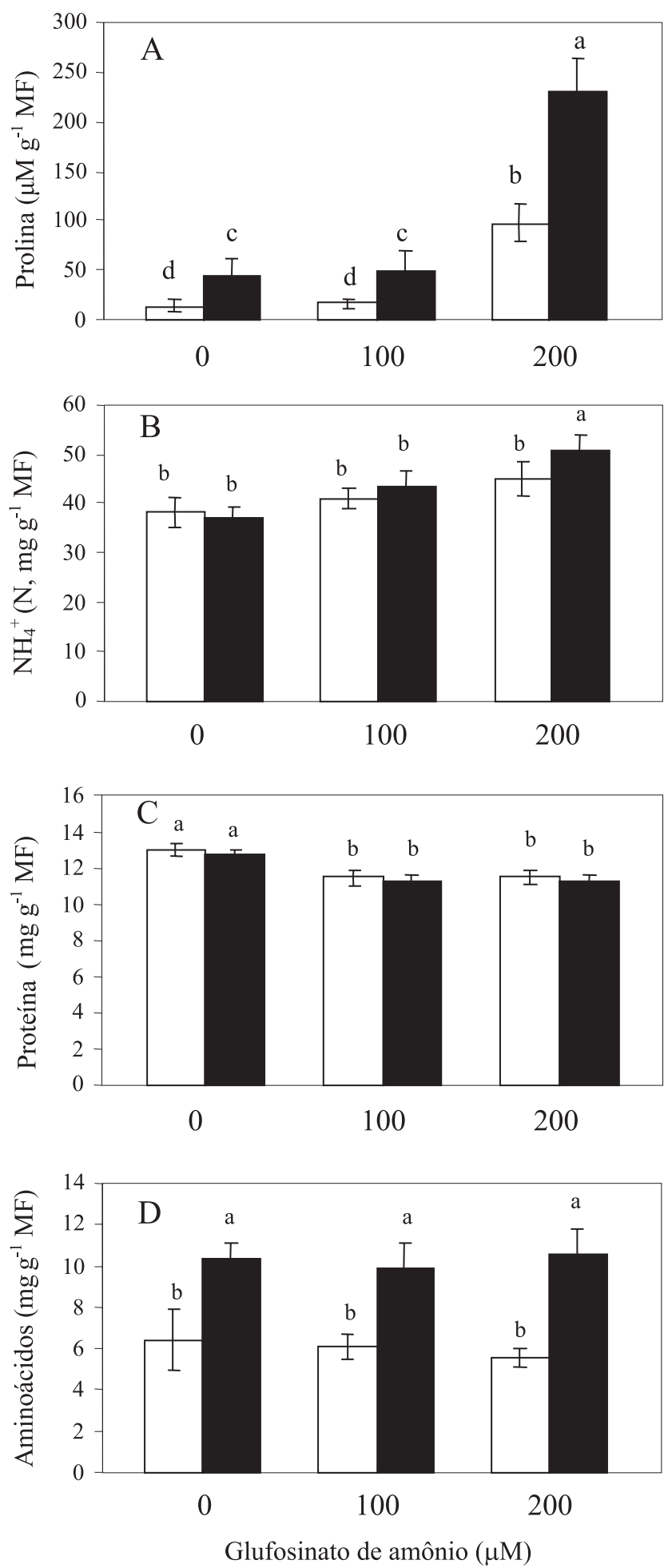

Figura 3. Análises químicas realizadas em plantas de citrumelo Swingle (Ct-P5-20), transformadas ( $\square$ ) e não-transformadas ( $\square$ ), submetidas a tratamentos com glufosinato de amônio. Os valores são apresentados como média \pm desvio-padrão. Tratamentos com a mesma letra não diferem significativamente pelo teste de Tukey a 5\% de probabilidade. 
resultados estão de acordo com os encontrados por Tsai et al. (2003), que demonstraram o aumento nas concentrações de prolina e de $\mathrm{NH}_{4}{ }^{+}$, em folhas de arroz após tratamento com glufosinato.

$\mathrm{O}$ maior acúmulo de $\mathrm{NH}_{4}{ }^{+}$apresentado em plantas transgênicas ocorreu, em parte, em conseqüência da hidrólise de proteínas e degradação de aminoácidos (Miflin \& Lea, 1977). Plantas tratadas com glufosinato apresentaram um decréscimo no teor total de proteínas, quando comparadas com as plantas tratadas com água (Figura $3 \mathrm{C}$ ).

Os maiores teores de aminoácidos totais foram encontrados em plantas transgênicas, com média de 10,23 $\mathrm{mg} \mathrm{g}^{-1} \mathrm{MF}$, independentemente dos tratamentos (Figura 3 D). Os dados obtidos mostraram diferenças significativas somente entre plantas transgênicas e nãotransgênicas. Estas diferenças nos teores de aminoácidos, nas folhas, devem estar relacionadas com o maior acúmulo de prolina nas plantas transgências. Como o catabolismo de aminoácidos é uma das fontes de acúmulo de $\mathrm{NH}_{4}{ }^{+}$, o glutamato gerado pela degradação de prolina, via enzimas prolina desidrogenase (ProDH) e pirrolina-5-carboxilato desidrogenase ( $\mathrm{P} 5 \mathrm{CDH})$, podem produzir quantidades elevadas de $\mathrm{NH}_{4}{ }^{+}$em plantas (Joy, 1988).
Desta forma, a degradação de glutamato em plantas transgênicas de citrumelo Swingle, com teores elevados de prolina, pode ser responsável pelo aumento do acúmulo de $\mathrm{NH}_{4}{ }^{+}$nas folhas tratadas com glufosinato. Esta hipótese é consistente com os resultados observados por Roosens et al. (1999), que mostraram que plantas estressadas de Nicotiana plumbaginifolia, com alto acúmulo de prolina em razão de mutação no gene $p 5 c s$, não apresentaram diferenças significativas nas concentrações de aminoácidos nas folhas, com exceção de prolina e glutamato.

Após cinco dias em presença de luz uniforme, os tecidos foliares de plantas-controle apresentaram poucos sinais de clorose em todas as concentrações de herbicida (Figura 4). Os tecidos foliares de plantas transformadas apresentaram $85 \%$ dos discos com clorose, nos tratamentos 100, 200 e $400 \mu \mathrm{M}$ de glufosinato de amônio, e $100 \%$ de clorose nos tratamentos com $800 \mu \mathrm{M}$ de glufosinato. Estes resultados comprovam a maior suscetibilidade de tecidos foliares de plantas transgênicas, com alto acúmulo de prolina ao glufosinato.

Além dos possíveis efeitos da hidrólise de proteínas e da degradação de prolina, no maior acúmulo de $\mathrm{NH}_{4}{ }^{+}$, outras hipóteses podem ser sugeridas para explicar a maior susceptibilidade ao glufosinato de amônio, por plan-

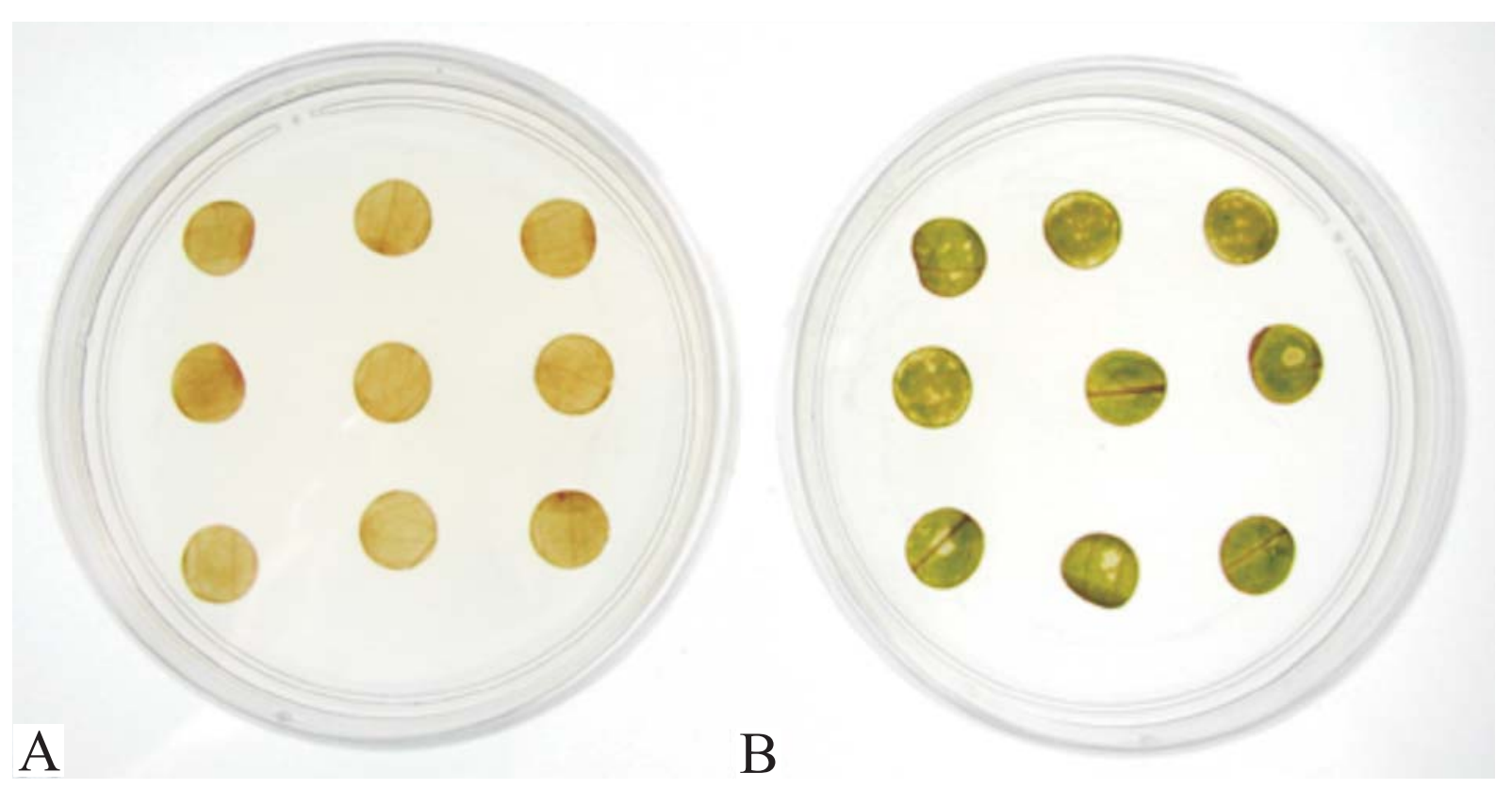

Figura 4. Análise da sensibilidade ao glufosinato de amônio, de discos foliares de plantas de citrumelo Swingle, em meio de cultura, após 5 dias de incubação com $800 \mu \mathrm{M}$ de fosfinotricina. A: plantas transformadas; B: plantas nãotransformadas. 
tas transgênicas com superprodução do aminoácido prolina, em conseqüência da superexpressão do gene $p 5 c s$. O glufosinato de amônio, depois de ser fosforilado pela enzima glutamina sintetase, se comporta como um inibidor irreversível desta enzima, por meio do deslocamento do glutamil fosfato do sítio ativo (Manderscheid \& Wild, 1986). Como a atividade $\gamma$-glutamil quinase, da enzima bifuncional P5CS, também catalisa a fosforilação ATP-dependente de glutamato, para formar o intermediário glutamil fosfato (Hu et al., 1992), a enzima P5CS deve atuar da mesma forma que a glutamina sintetase, em relação ao glufosinato. Assim, a superexpressão da enzima mutante P5CS poderia intensificar o efeito do herbicida nas plantas transgênicas de citrumelo Swingle.

A superexpressão da enzima P5CS em plantas transgênicas e, conseqüentemente, a maior produção de prolina têm efeitos no acúmulo de $\mathrm{NH}_{4}{ }^{+}$em tecidos foliares, após o tratamento com glufosinato de amônio, tornando-as, assim, mais suscetíveis a este herbicida.

Apesar da ação do glufosinato de amônio sofrer influência de vários fatores em condições de campo, como microrganismos e condições climáticas (Köcher, 1983; Tebbe \& Reber, 1988), as plantas transformadas com o gene $p 5 c s$, por produzirem mais prolina e acumularem maior quantidade de $\mathrm{NH}_{4}{ }^{+}$nas folhas, podem sofrer restrições de ordem agronômica, quanto ao uso de herbicidas implicados com a inibição da enzima glutamina sintetase.

\section{Conclusões}

1. Plantas transgênicas de citrumelo Swingle, com superexpressão do gene $p 5 c s$, acumulam maiores teores de prolina nas folhas, em comparação a plantas nãotransgênicas.

2. O tratamento com o herbicida glufosinato de amônio aumenta as concentrações de prolina, de $\mathrm{NH}_{4}{ }^{+}$e de aminoácidos totais, em plantas transgênicas com alto acúmulo de prolina.

3. O acúmulo de prolina em plantas transgênicas de citrumelo Swingle aumenta a sensibilidade deste portaenxerto ao glufosinato de amônio.

\section{Agradecimentos}

A Suely A. Kudo, pelo auxílio na condução dos experimentos de transformação de plantas.

\section{Referências}

BATES, L.S.; WALDREN, R.P.; TEARE, I.D. Rapid determination of free proline for water stress studies. Plant and Soil, v.39, p.205207, 1973.

BRADFORD, M.M. A rapid and sensitive method for the quantitation of microgram quantities of protein utilizing the principle of proteindye binding. Analytical Biochemistry, v.72, p.248-254, 1976.

CRUZ, C.D. Programa GENES: aplicativo computacional em genética e estatística. Viçosa: UFV, 1997. 442p.

D'HALLUIN, K.; BLOCK, M. de; DELAUNEY, A.J.; VERMA, D.P.S. Proline biosynthesis and osmoregulation in plants. Plant Journal, v.4, p.215-224, 1993.

DENECKE, J.; JANSSEN, J.; LEEMANS, J.; REYNAERTS, A.; BOTTERMAN, J. The bar gene has selectable and screenable marker in plant engineering. Methods in Enzymology, v.216, p.415-426, 1992.

HARE, P.; CRESS, W.; STADEN, J. van. Proline synthesis and degradation: a model system for elucidating stress-related signal transduction. Journal of Experimental Botany, v.50, p.413-434, 1999.

HOOD, E.E.; GELVIN, S.B.; MELCHERS, L.S.; HOEKEMA, A. New Agrobacterium helper plasmids for gene transfer to plants. Transgenic Research, v.2, p.208-218, 1993.

HU, C.A.; DELAUNEY, A.J.; VERMA, D.P.S. A bifunctional enzyme ( $\Delta^{1}$-pyrroline-5-carboxylate synthetase) catalyzes the first two steps in proline biosynthesis in plants. Proceedings of the National Academy of Sciences of the United States of America, v.89, p.9354-9358, 1992.

JOY, K.W. Ammonia, glutamine and asparagine: a carbon-nitrogen interface. Canadian Journal of Botany, v.66, p.2103-2109, 1988.

KISHOR, P.B.K.; HONG, Z.; MIAO, G.H.; HU, C.A.A.; VERMA, D.P.S. Overexpression of $\Delta^{1}$-pyrroline-5-carboxylate synthetase increases proline production and confers osmotolerance in transgenic plants. Plant Physiology, v.108, p.1387-1394, 1995.

KÖCHER, H. Influence of the light factor on physiological effects of the herbicide phosphinothricin ammonium. Aspects of Applied Biology, v.4, p.227-234, 1983.

LIN, C.C.; KAO, C.H. Regulation of ammonium-induced proline accumulation in detached rice leaves. Plant Growth Regulation, v.35, p.69-74, 2001.

LUTTS, S.; MAJERUS, V.; KINET, J.-M. NaCl effects on proline metabolism in rice (Oryza sativa) seedlings. Physiologia Plantarum, v.105, p.450-458, 1999.

MANDERSCHEID, R.; WILD, A. Studies on the mechanism of inhibition by phosphinothricin of glutamine synthetase isolated from Triticum aestivum L. Journal of Plant Physiology, v.123, p.135142, 1986.

MIFLIN, B.J.; LEA, P.J. Amino acid metabolism. Annual Review of Plant Physiology, v.28, p.299-329, 1977.

MOLINARI, H.B.C. Transformação genética de porta-enxertos para Citrus spp. visando obter maior tolerância ao estresse hídrico. 2003. 120p. Dissertação (Mestrado) - Universidade Estadual de Londrina, Londrina. 
MOLINARI, H.B.C.; BESPALHOK, J.C.; KOBAYASHI, A.K.; PEREIRA, L.F.P.; VIEIRA, L.G.E. Agrobacterium tumefaciensmediated transformation of Swingle citrumelo (Citrus paradisi Macf. $\mathrm{x}$ Poncirus trifoliata L. Raf.) using thin epicotyl sections. Scientia Horticulturae, v.99, p.379-385, 2004a.

MOLINARI, H.B.C.; MARUR, C.J.; BESPALHOK FILHO, J.C.; KOBAYASHI, A.K.; PILEGGI, M.; LEITE JÚNIOR, R.P.; PEREIRA, L.F.P.; VIEIRA, L.G.E. Osmotic adjustment in transgenic citrus rootstock Carrizo citrange (Citrus sinensis Osb. x Poncirus trifoliata L. Raf.) overproducing proline. Plant Science, v.167, p.1375-1381, 2004b.

MOORE, S.; STEIN, W.H. A modified ninhydrin reagent for the photometric determination of amino acids and related compounds. Journal of Biological Chemistry, v.211, p.907-913, 1954.

ROOSENS, N.H.; WILLEM, R.; LI, Y.; VERBRUGGEN, I.; BIESEMANS, M.; JACOBS, M. Proline metabolism in the wildtype and in a salt-tolerant mutant of Nicotiana plumbaginifolia studied by ${ }^{13} \mathrm{C}$-nuclear magnetic resonance imaging. Plant Physiology, v.121, p.1281-1290, 1999.
SAMBROOK, J.; FRITSCH, E.F.; MANIATIS, T. Molecular cloning: a laboratory manual. $2^{\text {nd }}$ ed. Cold Spring Harbor, NY: Cold Spring Harbor Laboratory, 1989. 3v.

TEBBE, C.C.; REBER, H.H. Utilization of the herbicide phosphinothricin as a nitrogen source by soil bacteria. Applied Microbiology and Biotechnology, v.29, p.103-105, 1988.

TSAI, Y.-C.; HSU, Y.T.; KAO, C.H. Proline accumulation induced by phosphinothricin in rice leaves. Biologia Plantarum, v.46, p.317319, 2003.

YOSHIBA, Y.; KIYOSUE, T.; NAKASHIMA, K.; YAMAGUCHISHINOZAKI, Y.; SHINOZAKI, K. Regulation of levels of proline as an osmolyte in plants under water stress. Plant and Cell Physiology, v.38, p.1095-1102, 1997.

ZHANG, C.-S.; LU, Q.; VERMA, D.P.S. Removal of feedback inhibition of $\Delta^{1}$-pyrroline-5-carboxylate synthetase, a bifunctional enzyme catalyzing the first two steps of proline biosynthesis in plants. Journal of Biological Chemistry, v.270, p.20491-20496, 1995.

Recebido em 19 de abril de 2005 e aprovado em 23 de dezembro de 2005 